V.

Aus der psychiatrischen und neurologischen Klinik der Universität in Kolozsvár (Ungarn). (Direktor: Hofrat Karl Lechner.)

\title{
Unterschiede zwischen dem Blutserum von Para- lytikern und Praecoxen in Bezug auf die Auslösung von Immunhämolysinen.
}

\author{
Von \\ Dr. Ladislaus Benedek und Dr. Stefan Deák, \\ Assistenten der Klinik.
}

Im Januar 1911 begannen wir Untersuchungen zusammen mit Herrn Assistent Dr. J. Borsos, die wir beide jedoch allein fortsetzten, da er im Beginn der Arbeit fortzog.

Das Ziel unserer Untersuchungen war, die sich anf Tierimpfungen mit dem Blutserum von Paralytikern entwickelnden pathologisch-anatomischen Veränderungen, eventuelle Stoffwechselanomalien, das Verhalten der durch diese Blutsera erzengten Immunsera homologen und heterologen roten Blutkörperchen gegenüber und in Gegenwart der verschiedenen Lipoid- und Kolloidstoffe zu studieren.

Den Impuls zu den Untersuchungen gaben Max Kauffmanns Beobachtungen, der durch solche Impfungen entstandene pathologischanatomische Veränderungen beschreibt (siebe Kaufmann, Beitr. zur Path. des Stoffwechsels bei Psychosen. 1. Bd. 1908).

Auf die Intention des Herrn Prof. Dr. Karl Lechner dehnten wir unsere Untersuchungen auch auf die Dementia praecox aus, weiterhin impften wir systematisch auch mit normalem menschlichem Blutserum Kaninchen, einerseits als Kontrolle, andererseits, weil einzelne Eigenschaften der so gewonnenen Immunsera gerade in der letzten Zeit den Gegenstand lebhafter Kontroversen bildeten.

Zur Immunisierung verwendeten wir koustant das Kaninchen.

Da schon in der ersten Versuchsreibe das Verhalten der von uns hergestellten Immunsera bisher noch nicht beschriebene Eigentümlichkeiten zeigte, wichen wir, da uns grösserer Erfolg lockte, von dem zuerst gesteckten Ziele ab, konzentrierten unsere Kraft hauptsächlich auf 
das letztere Ziel und suchten, ob die später zu beschreibenden Zusammenhänge konstant, und wenn ja, welche Erklärung wir ihnen geben könnten, oder wenigstens wie wir sie in den Rahmen ähnlicher, bisher beschriebener Resultate hineinstellen könnten.

Durch das Fallenlassen der Stoffwechseluntersuchungen gewanuen wir grössere Freiheit in der Benutung der verschiedenen Erscheinungsformen der einzelnen Krankheitsformen.

$\mathrm{Za}$ unseren Versuchen verwendeten wir von beiden Krankheitsformen nur die typischen und sicheren Fälle, also von Paralyse diejenigen, wo ausser den sicheren anamnestischen Daten noch die läugere Beobacbtung die Progredienz der Krankheit und die charakteristischen somatischen und psychischen Erscheinungen endgültig sicherstellte, und bei denen der serologische Befund des Blutes positiv war. Dass wir auf letzteres mit Recht grosses Gewicht legten, geht aus den Worten Kraepelins hervor: "Ergibt diese keine Komplementablenkung. so muss eine echte Paralyse als äusserst unwahrscheinlich bezeichnet werden". Unter den typisehen Fällen machten wir keinen Unterschied zwischen den klinischen Formen (expansiv, depressiv, demens, agitans). Die senilen und stationären Formen mieden wir als atypisch.

Schwieriger ist gegenwärtig die Bezeichnung der typischen Fälle von Dementia praecox. Die. Schwierigkeit hängt in erster Linie mit den Einwendungen zusammen, die in letzter Zeit gegen die Bezeichnung der Krankheitsform gemacht worden sind, und die sich bemühen, die nosologische Einheit der Dementia praecox anzugreifen. Es ist ja eine allgemein bekannte Tatsache, dass zahlreiche Fälle beobachtet werden, welche ohne jedes Zeichen der fortschreitenden Dementia verlaufen, andererseits macht nach dem von Kraepelin an der Hand von 296 Fällen hergestellten Altersdiagramm die Summe der Fälle über 25 Jahre zusammen 40 pCt. der Gesamtsumme aus (siehe Kraepelin, Psychiatrie. 7. Auflage. 1904. Bd. 2. S. 265)

Ausserdem erschwert die Diagnose noch der Umstand, dass das Krankheitsbild oft von Symptomen eingeleitet wird, die für zirkuläres Irresein charakteristisch sind, ja sogar nicht nur akzidentell im akuten Stadium der Krankheit, sondern Jahre bindurch allein und konstant das Krankheitsbild beherrschen, wie Urstein betont (Urstein, Die Dementia praecox und ihre Stellung zum manisch-depressiven Irresein. 1909) und nur später treten katatonische Ausfallserscheiuungen dazu; wie Löwy es darlegt, können sich diese sogenannten "Begleitpsychosen" bei der Dementia praecox sogar dauernd mit den Ausfallserscheinungen kombinieren, einander verdeckend. Nach ihm sind diese funktionellen psychotischen Erscheinungen in der psychopathischen Konstitution begründet. 
Dieser Umstand fällt um so schwerer ins Gewicht, weil die ersten Erscheinungen des zirkulären Irreseins gerade in die Pubertätszeit fällt, worauf E. Meyer binweist (Meyer, Die Ursachen der Geisteskrankheiten. S. 24), also gerade in das Lebensalter, das mit der Dementia praecox in engem kausalen Zusammenhang steht. In neuerer Zeit wird, sogar von einer "zyklischen" Form der Dementia praecox gesprochen, und es sind Fälle beschrieben, wo ausgesprochene katatonische Erscheinungen, äbnlich dem zirkulären Irresein, biervon jedoch gut abtrennbar, eine gewisse Periodizität zeigen. (Siehe Dunton, The cyclic. form of Dementia praecox. The american Journ. of insanity. 66. Vol. p. 465. 1910 und Barnes ebendort 65. Vol. 1909.)

Neben diesen können wir die Meinung derer nicht verschweigen, die das Kardinalsymptom dieser Krankheitsform nicht so sehr in der fortschreitenden Dementia, als vielmehr in der sich in Assoziationsfunktionen zeigenden Mangelhaftigkeit der Konzentrationsfähigkeit suchen, während der Konstruktionscharakter der geistigen Tätigkeit noch lange normal bleiben kann. (Siehe llaeder, Jahrbuch f. psycho-analytische und psychopathologische Forschung. Bd. 2.) Hierauf weisen übrigens auch die Bezeichnungen "Schizophrenie" von Bleuer, weiter "intrapsychische Ataxie" von Urstein hin. Hierher gehört auch der zur Zeit. nur mit grosser Vorsicht verwendbare histologische Befund von Zingerle, nach welchem die Zerstörang der in den äusseren Rindenzonen verlaufenden Assoziationsfasern - in seinem pathologisch-histologisch verarbeiteten Falle - nicht im Verbältnis zu den Zellläsionen steht, was nach seinen Ausführungen Licht auf den dissoziativen Charakter der Krankheit wirft. Solche histologischen Befunde haben ausser ihm auch andere (so Goldstein 1905 und 1910) veröffenlicht. Weiterhin sieht Stransky in der bei vier Fällen von Dementia praecox von Wada gefundenen und auf die Stirnlappen lokalisierten Rindenaffektion eine Störung des psychischen Koordinationszentrums. (S. Ref. Neurol. Zentralbl. 1910. S. $543-544$.

Bei der Verarbeitung unserer Fälle gingen wir von rein praktischen Gesichtspunkten aus, im Gegensatz zu diesen, zum grossen Teil noch theoretischen, oft spekulativen, psychoanalytischen Argumenten; indem wir das Hauptgewicht auf die progressive Demenz legten, verwendeten wir sowohl die durch katatonische Erscheinungen charakterisierten, als auch die rein hebephrenen Formen, aber immer zogen wir nur die Fälle in den Kreis unserer Untersuchungen, von deren Typizität wir durch längere, eventuell sich auf Jahre erstreckende Beobachtung schon retrospektiv überzeugt waren, indem wir die auf Grund der Imbezillität sich entwickelnden, sowie die paranoiden Formen ausliessen. 
Unser Krankenmaterial bot uns hauptsächlich die Klausenburger psychiatrische Klinik; da unsere Klinik jedoch hauptsächlich Studienzwecken dient, und so nicht ihre Aufgabe sein kann, die zu den einzelnen Krankheitsformen gehörenden Kranken zu sammeln, so verschaffte uns, auch wegen der obigen Auswahl hauptsächlich die Dicsöszentmártoner, in einem Falle die Grosswardeiner Heilanstalt das fehleude Material, und wir sprechen auch an diesem Orte den Herren Direktoren und Oberärzten der beiden Anstalten, besonders den Herren Dr. M. Szöts, Dr. St. Zsakó, Dr. E. Fráter, Dr. K. Kenéz unseren besten Dank aus.

Normales menschliches Blutserum entnahmen wir dem Dienstpersonal unserer Anstalt. Mit jedem Serum machten wir zunächst die Wassermannsche Reaktion, und nur wenn diese ausgesprochen negativ war, verwendeten wir es zur Tierimpfung.

Im ganzen haben wir 45 Kaninchen mit dem Blute von zusammen 150 verschiedenen Individuen behandelt. Natürlich haben wir innerhalb dieser Zahl von demselben Kranken öfter Blut genommen. Drei Reihen von Impfungen machten wir. Die Sera applizierten wir intraperitoneal, alle 5 Tage 8-10 ccm. In je einer Versuchsreihe gaben wir einem Tier $5-6$ Injektionen.

Da unsere Ergebnisse in allen drei Versuchsreihen dieselben waren, so teilen wir der leichteren Uebersicht wegen nur die Tabellen mit den Ergebnissen der letzten Reihe mit, in welcher wir zusammen 15 Kaninchen behandelten, und zwar 2 mit normalem menschlichen Butserum, 6 mit dem Blutserum von Paralytikern, 7 mit dem Serum von Praecoskranken. Von 45 Tieren sind im ganzen nur 2 zu Grunde gegangen, von denen eines mit dem Serum eines Paralytikers, das andere mit dem eines Praecoxen behandelt war. Die Sektion wies bei beiden profuse Eiterung des Bauchdeckenbindegewebes und Peritonitis nach. Ausserdem haben noch drei Kaninchen trotz Vorsicht umschriebene Bauchdeckeneiterung bekommen, welche auf die Umgebung des Stichkanals lokalisiert blieb. (Eines war mit paralytischem, zwei mit praecoxem Serum geimpft.) Diese Zahlen sind zu klein, um daraus auf eine, durch die Behandlung hervorgerufene, herabgesetzte Widerstandsfähigkeit Eiterungen gegenüber schliessen zu dürfen, beide Krankheitsformen in Betracbt gezogen. Schon bei umschriebenen Eiterungen schlossen wir 'das Tier von den weiteren Versuchen aus.

Wir halten es für wichtig mitzuteilen, dass die mit Blutserum von Paralytikern geimpften Kaninchen im Gegensatz zu den anderen auffallend, ohne Ausnahme abnahmen, die Gewichtsabnahme betrug 200 bis $500 \mathrm{~g}$. 
Unterschiede zwischen dem Blutserum von Paralytikern und Praecoxen. 213

Die Gewichtsveränderungen der mit praecoxem Serum behandelten Tiere bewegten sich in annähernd normalen Grenzen. Nachdem wir mit den Gliedern der letzten 15er Gruppe die bämoly tischen Versuche gemachthatten, töteten wir sie, ohne Narkose, da wir die Gehirne pathologisch-histologisch verarbeiten wollten, - ibre Sektion war mit Ausnahme von zweien negativ. Die beiden waren mit praecoxem Serum behandelt, und die Sektion ergab eine stark ausgesprochene parenchymatöse Entzündung der Nieren. Es entspricht dies den Versuchsdaten von 0 . Weiss, der nach Injektionen von heterogenem Serum regelmässig Albuminurie beobachtete (siehe 0 . Weiss, „Ueber die Wirkung von Blutseruminjektionen ins Blut". Pflügers Archiv 65. Bd. [1896]. S. 215 und "Ein Nachtrag zu den Untersuchungen über die Wirkung von Blutseruminjektionen ins Blut". Pflügers Archiv 68. Bd. 1907 S. 348). Pueumonie, Keratitis, von welchen Max Kauffmann in einigen Fällen von Impfungen von Kaninchen, Hund und Meerschweinchen mit paralytischem Blutserum berichtet, konnten wir trotz genauer Beobachtung nicht finden. Die Gehirne der geimpften Kaninchen fixierten wir in 8 proz. Formalin, Müllerscher Flüssigkeit, beziehungsweise absolutem Alkohol, und beabsichtigen sie pathologisch-histologisch zu verarbeiten; eventuelle Ergebnisse werden wir in einer unserer nächsten Arbeiten veröffentlichen. In der Technik unserer Arbeiten folgten wir den Anweisungen von Uhlenhuth und Weidanz, weiterhin von Citron and Sachs, deren zusammenfassende Beschreibung in dem von Kraus und Levaditi herausgegebenen Werke „Handbuch der Immunitätsforschung" erschienen ist.

\section{Erster Versuch.}

Nachdem wir in fünftägigen Intervallen zusammen fünf Impfungen gemacht batten, und uns durch eine orientierende Blutprobe überzeugten, dass die gewonneven Immunsera die Reaktion noch immer nicht ausgeprägt genug gaben, machten wir noch eine sechste Injektion. Nach einer viertägigen Inkubationszeit zeigten die Blutsera folgende Eigenschaften bei folgender Versuchsanordnung:

$\mathrm{Zu}$ den Sera der Kaninchen, welche wir mit paralytischem, praecoxem und normalem menschlichen Blutserum behandelt haben, und als Kontrolle zu normalem Kaninchenblutserum in den Mengen von 0,1, $0,2,0,3,0,4 \mathrm{ccm}$ gaben wir $1,5 \mathrm{ccm}$ einer 5 proz. Suspension von roten Blutkörperchen eines Paralytikers, eines praecoxen und eines normalen Menschen, immer mit gleichen Volumina arbeitend, d. h. wir ergänzten das Inmunserum mit isotonischer Kochsalzlösung $(0,85 \mathrm{pCt}$ ) auf $1 \mathrm{ccm}$. Den Inhalt der Reagenzgläschen schüttelten wir gut zusammen und stellten sie in den Thermostat, der auf das Optimum der Hämolyse, 37 
bis $33^{\circ}$ C., eingestellt war. Alle balbe Stunden wurden die Reagenzgläschen von neuem aufgeschüttelt, der etwa vorbandenen Agglutinine wegen; nach 2 Stunden nahmen wir sie aus dem Thermostat heraus und liessen sie etwa 8-9 Stunden an einem kalten Orte stehen, während welcher Zeit die vollständige Sedimentierung der ungelösten roten Blutkörperchen vor sich ging und die Ablesung des Resultates erleichterte. Zur Vergleichung brachten wir in eine Reihe das Serum des mit paralytischem Blutserum geimpften Kaninchens Nr. 15, das Serum des hellaschgrauen Kaninchens No. 21, welches mit praecoxem, weiterhin das des dunkelaschgrauen Kaninchens, welches mit normalem menschlichen Blutserum behandelt war, zum Schluss das Serum des wildgrauen, nicht behandelten Kaninchens mit obigen roten Blutkörperchen zusammen.

Nach nebenstehender Tabelle sind ausgesprochene, auffällige Unterschiede in hämolytischen Eigenschaften der Immunsera der mit paralytischem, praecoxem und mit normalem menschlichen Blutserum behandelten Kaninchen, denn während das Serum der nur mit dem Blatserum von Paralytikern Behandelten die roten Blutkörperehen "noch nicht", „in Spuren" oder nur "sehr schwach" löst, sehen wir die Hämolyse des praecoxen Immunserums mit den Bezeichnungen „schwach", „stark", „sehr stark" und "beinahe komplett" versehen.

Die durch die Blutsera der mit normalem menschlichen Blutserum geimpften Kaninchen hervorgerufene Hämolyse variiert zwischen den Graden „in Spuren“ bis zu den niederen Graden von "inkompletter Lösung".

Das Serum der normalen Kaninchen zeigte absolut keine Hämolyse, oder höchstens in Spuren, welche durch die über den roten Blutkörperchen stehende lackfarbene Zone* charakterisiert ist.

Die einzelnen Immunsera zeigen ausser den geschilderten Aenderungen in der Stärke der Hämolyse noch einen anderen, sehr interessanten Zusammenhang. Wir sehen nämlich, dass sich im Titer der Hämolyse, auch gemäss der roten Blutkörperchen noch auffällige Unterschiede zeigen, denn während im allgemeinen die Lösungen der paralytischen Blutkörperchen unter den, die betreffenden Gruppen charakterisierenden Lysen immer die niedersten Werte zeigen, so stehen die praecoxen roten Blutkörperchen immer an erster Stelle, die Lysis der normalen roten Blutkörperchen steht zwischen den beiden, und zwar immer den niederern Werten näher.

Der obige Zusammenhang scheint auf strenger Spezifiät zu beruhen, weil wir als Endresultat folgendes daraus entnehmen können: dass die Hämolyse der gegen das paralytische Serum gebildeten Immunsera am geringsten ist paralytischen roten Blutkörperchen gegenüber, die 
Unterschiede zwischen dem Blutserum von Paralytikern und Praecoxen. 215
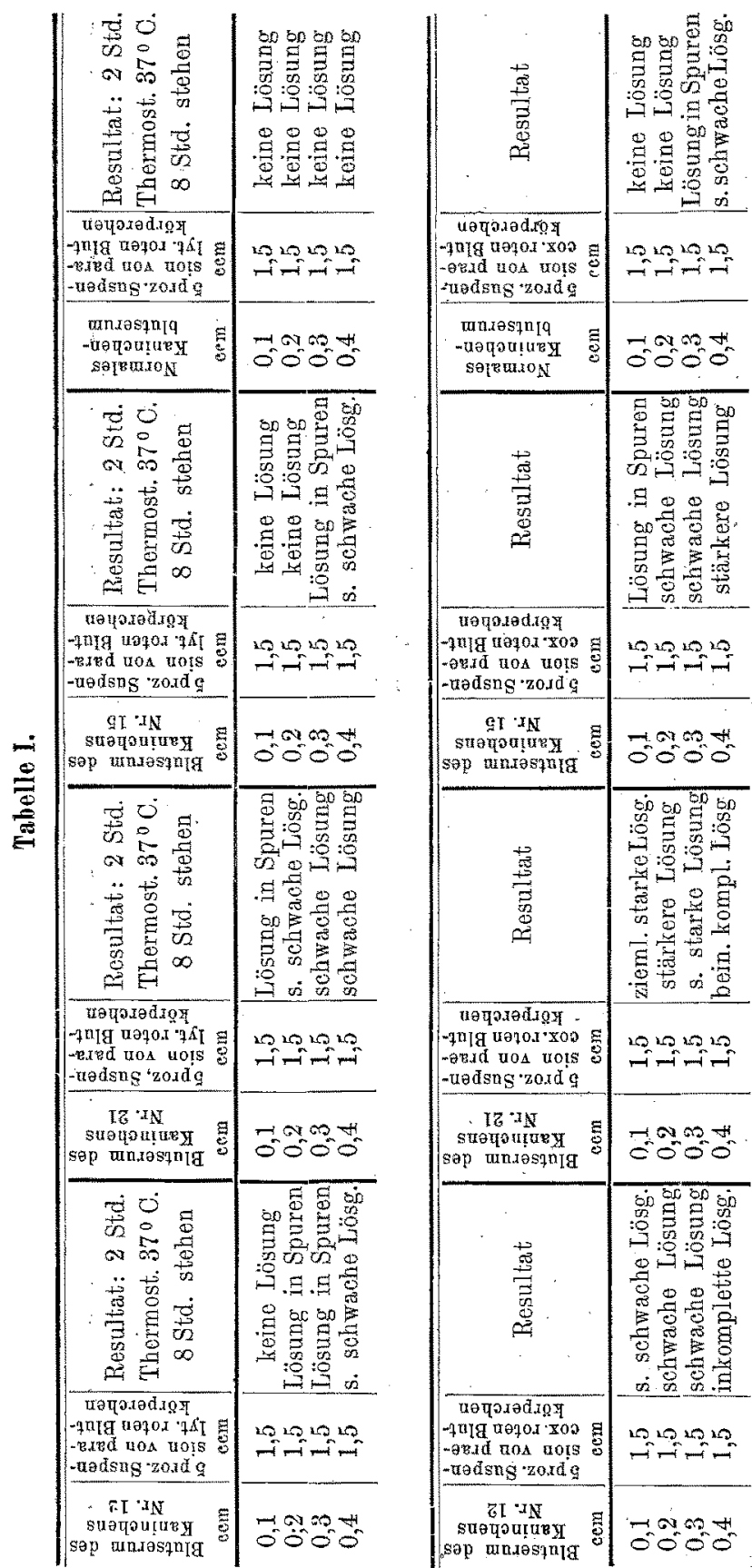

\begin{tabular}{|c|c|}
\hline 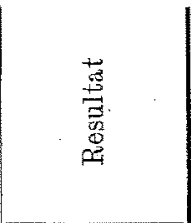 & 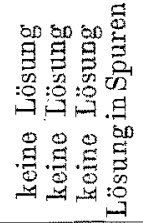 \\
\hline 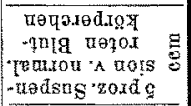 & 10201020 \\
\hline 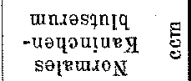 & $\begin{array}{l}0000 \\
000\end{array}$ \\
\hline 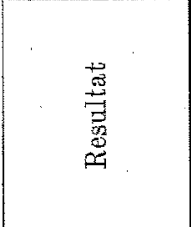 & 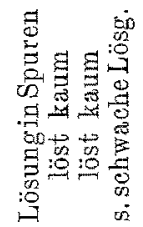 \\
\hline 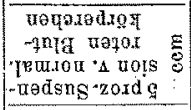 & (20) \\
\hline 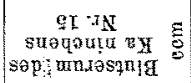 & - 0000 \\
\hline 趈 & 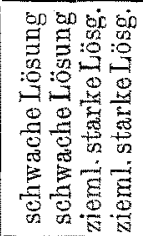 \\
\hline 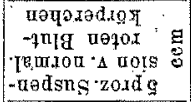 & $\log _{-1} 10210$ \\
\hline 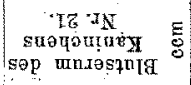 & $\begin{array}{l}-0007 \\
0000\end{array}$ \\
\hline 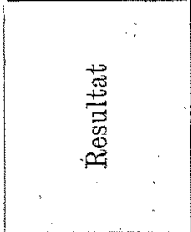 & 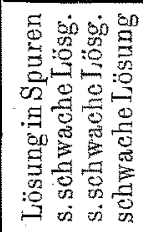 \\
\hline 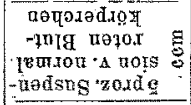 & 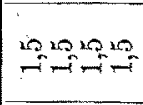 \\
\hline $\begin{array}{c}\text { ZI:IN } \\
\text { suәqoutuex } \\
\text { sep unaesqnid }\end{array}$ & - \\
\hline
\end{tabular}


Hämolyse der gegen praecoxes Serum sich gebildeten Immunsera am höchsten ist praecoxen roten Blutkörperchen gegenüber. Schliesslich sehen wir, dass die Stärke der Hämolyse unserer Immunsera mit dem. Steigen der Gewichtsmengen proportional steigt.

Die Resultate aus der letzten Gruppe unserer Impfungen bei obiger Versuchsanordnung zeigt neben obiger Tabelle, welche sich nur auf die Immunsera von vier Kaninchen bezog, die folgende Tabelle, welche sämtliche Kaninchen der letzten Gruppe umfasst.

Die obigen Immunsera waren am besten ganz frisch zu den obigen Reaktionen zu verwenden, zwei Tage hindurch bewahrten sio ihre hämolytischen Eigensehaften noch ganz gut, am dritten Tag wurden sie gewöhnlich schwächer, die Resultate der am 4. und 5. Tage gemachten Versuche waren nicht mehr zu verwerten. Als Endpunkt der Inkubationszeit mussten wir den vierten Tag annehmen, in weleher Zeit in uuseren Versuchen die Sera das Maximum an Hämolysingehalt zeigten, auch der fünfte Tag brachte in dieser Hinsicht noch gute Resultate, der sechste Tag erwies sich gewöhnlich als zu spät.

Wir halten es für wichtig, hier zu erwähnen, dass die obigen Eigenschaften sowobl bei der Ausdehnung der Inkubationszeit, als auch beim Stehen der Immunsera am besten die Immunsera der mit praecoxem Blutserum belaandelten Kaninchen bewahrten.

So fanden wir weiter, dass die roten Blutkörperchen der zu den Impfungen verwendeten Kranken zum Versuche weniger geeignet waren, so dass wir später besonders darauf achteten, dass wir die roten Blutkörperchen von ganz anderen Individuen entnahmen.

Alles sprach dafür, dass sich im Blutserum der immunisierten Tiere Komplexhämolysine entwickelt hatten, und dass diese in unseren Versuchen wirkten. Um uns davon zu überzeugen, inaktivierten wir einen Teil unserer Immunsera und brachten diese mit den roten Blutkörperchen zusammen in obiger Volummenge und bei derselben Anordnung. Das Resultat war - wie vorauszuseben - vollständig negativ, das heisst die roten Blutkörperchen bildeten agglomeriert ein Sediment auf dem Boden der Reagenzgläschen. Die inaktivierten Immunsera reaktivierten wir mit frischem Meerschweinchenkomplement, und zwar mit den Volummengen 0,1 , beziehungsweise in einer zweiten Reihe mit 0,2 ccm. (Das Meerschweinchenserum schien dazu auch darum besonders geeignet zu sein, weil es bekanntlich neben seinem reichen Komplementgehalt nur minimale Mengen von normalen Hämolysinambozeptoren enthält, und die bei den feinen Unterschieden bei der obigen Reaktion a priori wichtig schien.) Die Reaktivierung hatte Erfolg, indem das Resultat, zwar schwächer ausgeprägt, so doch dasselbe war. 


\section{Tabelle II.}

Die Einteilung nach Zahlen bezieht sich auf die Gewichtsmengen $0,1,0,2,0,3,0,4$, die Bezeichnung mit Buchstaben zeigt der Reihe nach die Resultate der Hämolyse, paralytischen, praecoxen und normalen roten Blutkörperchen gegenüber nach 2 Stunden $37^{\circ}$ Thermostat und 8 stïndigem Stehen. Also z. B. $3 \alpha, 3 \beta, 3 \gamma$, bezieht sich immer auf $0,1 \mathrm{~cm}$ Serum; $-3 \mathrm{a}, 3 \mathrm{~b}, 3 \mathrm{c}$ anf $0,2 \mathrm{ccm}$; III $\alpha$, III $\beta$, III $\gamma$ auf $0,3 \mathrm{ccm}$; und III 2 , III $b$, III 0 auf $0,4 \mathrm{ccm}$.

\section{Serum des Kaninchens Nr. 14.}

$3 \alpha$ keine Lösung

$3 \beta$ sehr schwache Lösung $3 \gamma$ schwache Lösung

3 a lost baum

$3 \mathrm{~b}$ sehr schwache Lösung $3 \mathrm{c}$ sehr schwache Lösung

[II $\alpha$ sehr schwache Lösung III $\beta$ schwache Lösung III $\gamma$ sehr leichte Lösung

III a sehr schwache Lösung III b schwache Lösung III 0 sehr leichte Lösung

\section{Serum des Kaninchens $\mathrm{Nr}, 15$.}

4 a keine Iiösung

$4 \beta$ lösung in Spuren

$4 \gamma$ Lösung in Spuren

4 a keine Lösung

$4 \mathrm{~b}$ löst kaum

$4 \mathrm{c}$ löst kaum

IV $\alpha$ Lösung in Spuren

IV $\beta$ schwache Lösung

IV $\gamma$ löst kaum

IV a sehr leichte Lösung

IV b schwache Lösung

IV c sehr schwache Loisung

\section{Serum des Kaninchens $\mathrm{Nr}, 17$.}

$5 a$ keine Lösung

5 f sehr schwache Lösung

$5 \gamma$ keine Lösung

5 a Lösung in Spuren

$5 \mathrm{~b}$ sehr schwache Lösung

50 löst kaum

$\checkmark \alpha$ löst kaum

$\mathrm{V} \beta$ schwache Lösung

Vr sehr schwache Lösung

Va sehr schwache Lösung

Vb schwache Lësung.

Vo schwache Lösung
Serum dos Kaninchens

$$
\text { Nr. } 18 .
$$

$6 \alpha$ keine Lösung

$6 \beta$ Lösung in Spuren

$6 \gamma$ keine Lösung:

6 a löst kaum

$6 \mathrm{~b}$ sehr leichte Lösung

6 e Lösung in Spuren

VI $a$ sehr schwache Lösung

VI $\beta$ schwache Lösung

VI

VI a sohr schwache Lösung

VIb schwaehe Lösung

VI c schwache Lösung

\section{Serum des Kaninchens $\mathrm{Nr} .11$.}

1 a sehr leichto Lösung

$1 \beta$ schwache Lösung

$1 \gamma$ sehr schwache Lösung

1 a schwache Lösung

$1 \mathrm{~b}$ schwache Lösung

$1 \mathrm{c}$ schwache Lösung

Ia schwache Lösung

If ziemlich starke Lobung

Ir sehwacho Lösung

I a stärker inkompl. Lösung

Ib stärker inkompl. Lösung

I e stärker inkompl. Lösung

\section{Sermm des Kaninehens} $\mathrm{Nr} .2$.

$2 a$ keine Lösung

$2 \beta$ sehr schwache Lösung

$2 \gamma$ sehr schwache Lösung

2 a Lösung in Spuren

$2 b$ schwache Lösung

20 Lösung in Spuren

II $\alpha$ sehr schwache Lösung

II $\beta$ schwache Lösung

II $\gamma$ sehr sehwache Lösung

II a schwacho Lösung

IIb inkompl. Lösung

IIe sehwache Lösung

\section{Serum des Kaninchens} Nr. 19.

7 a schwache Lösung

$7 /$ inkompl. Lösung

$7 \gamma$ schwache Lösung

7 a stärkere Lösung

$7 \mathrm{~b}$ starke Lösung

7 e inkompl. Lüsung

VII $a$ starke Lösung

VIT $\beta$ beinahe kompl. $L$.

VII ${ }_{\gamma}$ beinahe kompl. L.

VIla beinahe kompl. $L$.

VII b rompl. Lösung

VIIc beinahe kompl. L.

\section{Serum des Kaninchens} Nr. 20.

$8 a$ sehr schwache Lösung

$8 \beta$ sehwache Lösung

$8 \gamma$ sehr schwache Lösung

8 a schwache Lösung

$8 \mathrm{~b}$ stärkere inkompl. L.

8 a schwache inkomp. L.

VIII $\alpha$ ziemlich starke L.

VIII $\beta$ starke Lösung

VIII stärkere inkompl. L.

VIII a starke Lösung

VIIIb kompl. Lösung

VIII o beinahe kompl. L.

\section{Sermm des Kaninchens}

$$
\text { Nr. } 21 .
$$

$9 \alpha$ Lösung in Spuren

$9 \beta$ sehr leichte Lösung

$9 \gamma$ löst kaum

9 a sehr schwache luösung

$9 \mathrm{~b}$ schwache Lösung

90 sehr schwache Lösung

IX $\alpha$ schwache l.ösung

IX $\beta$ stärker inkompl. L.

IX $\gamma$ schwach inkompl. L

IX a sehwache Lösung

IX b starke Lösung

IXo stâkere inkompl. L. 
Die schwächere Hämolyse kann so erklärt werden, dass die Hämolysine der Inaktivierung gegenüber nicht die gleiche Thermostabilität zeigen; so ist bekannt, dass z. B. normale Hämolysine oft bei $55^{\circ} \mathrm{C}$. in einer halben Stunde mit ihrer Aktivität auch die Fähigkeit, reaktiviert zu werden, verlieren. Die Hämolysine, die Michelis und Fleischmann mit den Zellen verschiedener Organe herstellten, waren auch weniger thermostabil.

Wir achteten immer auch auf das makroskopische Aussehen der Sedimente, sowohl hier, als auch bei dem negativen Ausfall der Reaktionen der ersten Tabelle. Man hätte zwar in diesem Falle auch an gleichzeitige Bildung von hämolytischen Agglutinen denken können (siehe unten die Hämolysinbildung), welche zwar in vivo während der Produktion mit den Hämolysinen nicht konkurrieren (siebe Wendelbachs Beobachtung), in vitro sie jedoch desto eher hätten bindern können, wenn auch nur physikalisch (siebe Sachs).

Wir wissen weiterhin, dass hämolytische Agglutinine (hetero-, iso - und auto-) auch in ganz normalem Blutserum vorkommen (Strauss, Wolf, Hedinger, Marshall, Landsteiner, Halban, Ascoli, Klein).

Nach den Untersuchungen von Bordet und Streng (Zentralblatt f. Bakteriol. 1909. Bd. 49) wissen wir auch, dass die normalen Blutsera von Tieren von den Agglutininen experimentell gut differenziert auch Konglutinine enthalten. Gerade auf letzterer Beobachtung beruht auch die Karvonensche "Konglutinationsreaktion", welche sich von der Wassermannschen Reaktion eigentlich nur durch den Indikator unterscheidet, und welche der Autor wegen der genauen Funktion der Konglutinine vor die Wassermannsche Reaktion stellt, obwohl es schwer zu glauben ist, dass ein konglutininartig wirkender Indikator empfindlicher sein solle, oder sogar mit grösserer Latitude reagieren solle, als der Farbenindikator, sei sie auch viel einfacber als die Wassermanusche Reaktion (Karvonen, Arcliv f. Dermatologie. 1911. In neuerer Zeit Siebert u. Hironescu, Deutsche med. Wochenschr. 1911. H. 45). Die Konglutinine würden auch nur ein mechanisches Hindernis bilden.

In den erwähnten negativen Befunden beobachteten wir Agglutination nur in zwei Fällen makroskopisch und mikroskopisch, so dass wir dies als einen ausserordentlichen Befund ansehen können. In der Regel nahm die Sedimentierung der ungelösten Blutkörperchen längere Zeit in Anspruch und zeigte das Bild der Agglomeration, im übrigen hatten wir die eventuelle ungünstige physikalische Wirkung der Agglutinine auf die Hämolyse durch $1 / 2$ stündiges Aufschütteln genügend kompensiert (Sachs), so dass wir ganz ausschliessen können, dass bei den obigen Resultaten die Agrglutinine eine Rolle spielten. 
Die Ergebnisse der ausgeführten "A ktivierungsmethode" rechtfertigten vollständig für jedes Immunserum die Annahme der Komplexhämolysine. Bevor wir uns in die Erklärung des merkwürdigen Verhaltens der letzteren einlassen, wollen wir noch folgendes einschalten:

Immunkörper gegen rote Blutkörperchen bekommen wir im allgemeinen durch Einführung roter Blutkörperchen in den Organismus; sie entwickeln sich schnell und in grosser Menge. Mit den öfters gewaschenen und vom Serum befreiten roten Blutkörperchen von paralytischen und praecoxen Individuen impften wir je 6 Kaninchen; das Immunserum von sämtlichen 12 wirkte tadellos hämolytisch. Die Lösung war bei jedem komplett, auch im hämolytischen Titer zeigte sich kein nennenswerter Unterschied, so dass in dieser Beziehung die Immunsera keine -Verschiedenheiten zeigten. Daraus folgt, dass der Mangel an Unterschieden in diesem Falle auf die zu starken hämolytischen Systeme zurückzuführen ist, bei viel weniger Rezeptoren und bei viel weniger starker hämolytischer Reaktion würden die Unterschiede zur Geltung kommen. Dungern, Tehistovitsch, Morgenroth, Schattenfroh u. a. gelang es zuerst, mit von den roten Blutkörperchen befreitem Serum und mit tierischen Säften gegen rote Blutkörperchen zytotrope Stoffe bzw. Lysine auszulösen. Die Erscheinung erklären sie im allgemeinen damit, dass Stromarezeptoren ins Blut gelangen. Bei der Immunisierung mit Blutserum spielen also diese die Rolle der Antigene. Diesem nach wäre also folgende Annahme plausibel: Da unter den von uns hergestellten Immunsera dasjenige der mit paralytischem Blutserum geimpften Tiere konstant geringeren Hämolysingehalt zeigt als die mit normalem Blutserum geimpften, würde folgen, dass in dem paralytischen Blutserum die als Antigene funktionierenden Stromarezeptoren in viel geringerer Zahl vorhanden sind, als in dem normalen Serum. Das praecoxe Serum verbält sich Obigem nach gerade umgekehrt, das heisst das Blutserum ist reich an Rezeptoren, die die Rolle von Hämolysinantigenen spielen. Aus unseren Versuchen könnten wir mit Recht auf diese Annahme schliessen, indem wir uns auf die Untersuchungen von Sachs, Friedberger und Dorner berufen, da bei dem Nachweis dieser Rezeptoren ihre Immunisierungsfäbigkeit ihrer antikörperbindenden Funktion überlegen ist. (In solchem Sinne lauten auch die Untersuchungen von Bang und Forssmann über die Wärmeresistenz der hämolytischen Antigene.)

Bevor wir jedoch diese Hypothese endgiltig annehmen, sehen wir einmal, welche Gegengründe dagegen vorgebracht werden können.

Man könnte sagen, dass hier die komplementbindende Fähigkeit der präzipitierenden Sera bzw. deren Unterschiede die oben beschriebene 
Differenz in der Hämolyse bedingen, mögen sie nun entweder im Sinne von Weil und Braun oder mechanisch zu stande kommen. Nach den Beobachtongen von Weil und Braun geben nämlich unter den präzipitierenden Sera die Blutsera der Tiere, die gegen Schweine-, Rind-, Menschen-, Hundeeiweiss immunisiert wurden, mit den auch bei der Wassermannschen Reaktion verwendeten alkoholischen Organextrakten Komplementbindung. Die Phänomene erkIären sie damit, dass die Einimpfung von fremdem Eiweiss in dem Tierorganismus auch die Produktion von lipoidophilen Stoffen verursache, welche, wenn sie mit Lipoiden zusammentreffen, ohne alle Spezifität Komplementbindung zeigen können. - Abgesehen davon, dass die Kontrolluntersuchungen von Michelis und Borelli, weiters ron Molnár sich in bezug auf das Verhalten der präzipitierenden Sera alkoholischen Extrakten gegenüber mit den Beobachtungen von Weil und Braun stark widersprechen, so sind die Vorbedingungen für das Zustandekommen der von uns beschriebenen Erscheinungen im Sinne von Weil und Braun gegeben, es ist nämlich mebreren gelungen, zu zeigen, dass die Stromarezeptoren Lipoide sind (siehe Dautwitz, Landsteiner, Forssmann, Bang), so dass man sich leicht vorstellen kann, dass diese als Lysogene das Blutserum unserer Kaninchen überschwemmend mit diesen supponierten lipoidopbilen Substanzen Komplementfixation geben. Um dies auszuschliessen (nach Dr. Molnár), injizierten wir intravenös Lezithin je einem gegen paralytisches, gegen praecoxes und gegen normales menschliches Blutserum immunisierten Kaninchen, sofort nach der ersten Blutentnahme, und nach 6 Stunden untersuchten wir wieder das Verhalten unserer Sera roten Blutkörperchen gegenüber. Die injizierte Lezithinmenge betrug $0,2 \mathrm{~g}$ (Mercksches Ovolezithin). Das Resultat zeigt die folgende Tabelle:

\section{Tabelle III.}

Die hämolytischej Wirkung der Blutsera der Kaninchen Nr. 15 (paralyt.), Nr. 19 (praec.), Nr. 11 (norm.) nach Lezithininjektionen (homologe rote Blutkörperchen).

\begin{tabular}{|c|c|c|c|}
\hline \multirow{2}{*}{$\begin{array}{l}\text { Blutserum des } \\
\text { Kaninchens } \\
\text { Nr. } 15 \text { (par.) } \\
\text { ccm }\end{array}$} & \multirow{2}{*}{$\begin{array}{l}5 \text { proz. Suspen- } \\
\text { sion von para- } \\
\text { lyt.roten Blut- } \\
\text { körperchen. } \\
\text { ecm }\end{array}$} & \multicolumn{2}{|c|}{ Resultat: $38^{\circ} \mathrm{C}$. Thermost. 2 Std. } \\
\hline & & Vor der Injektion & Nach der Injektion \\
\hline $\begin{array}{l}0,1 \\
0,2 \\
0,3 \\
0,4\end{array}$ & $\begin{array}{l}1,5 \\
1,5 \\
1,5 \\
1,5\end{array}$ & $\begin{array}{l}\text { keine Lösung } \\
\text { do. } \\
\text { in Spuren } \\
\text { sehr schwach }\end{array}$ & $\begin{array}{c}\text { keine Lösung } \\
\text { do. } \\
\text { in Spuren } \\
\text { sehr schwach }\end{array}$ \\
\hline
\end{tabular}


Unterschiede zwischen dem Blutserum von Paralytikern und Praecoxen. 221

\begin{tabular}{|c|c|c|c|}
\hline \multirow{2}{*}{$\begin{array}{l}\text { Blutserum des } \\
\text { Kaninchens } \\
\text { Nr. } 19 \text { (praec.) } \\
\text { ccm }\end{array}$} & \multirow{2}{*}{$\begin{array}{l}\text { 5proz.Suspen- } \\
\text { sion v. praec. } \\
\text { roten Blut- } \\
\text { körperchen } \\
\text { ccm. }\end{array}$} & \multicolumn{2}{|c|}{ Resultat: $38^{\circ} \mathrm{C}$. Thermost. 2 std. } \\
\hline & & Vor der Injektion & Nach der Injektion \\
\hline $\begin{array}{l}0,1 \\
0,2 \\
0,3 \\
0,4\end{array}$ & $\begin{array}{l}1,5 \\
1,5 \\
1,5 \\
1,5\end{array}$ & $\begin{array}{c}\text { schwache Lösung } \\
\text { stärker inkompl. Lösg. } \\
\text { starke Lösung } \\
\text { beinahe kompl. Lösg. }\end{array}$ & $\begin{array}{l}\text { sehwache Lösung } \\
\text { stärkere inkompl. Lösg. } \\
\text { starke Lösung } \\
\text { beinahe kompl. Lösg. }\end{array}$ \\
\hline
\end{tabular}

\begin{tabular}{|c|c|c|c|}
\hline \multirow{2}{*}{$\begin{array}{l}\text { Blutserum des } \\
\text { Kaninchens } \\
\text { Nr. } 11 \text { (norm.) } \\
\text { cero }\end{array}$} & \multirow{2}{*}{$\begin{array}{c}5 \text { proz.Suspens. } \\
\text { v. normalen } \\
\text { menschl. Blut- } \\
\text { körperchen } \\
\text { cem }\end{array}$} & \multicolumn{2}{|c|}{ Resultat: $38^{\circ} \mathrm{C}$. Thermost. 2 Std. } \\
\hline & & Vor der Injektion & Nach der Injektion. \\
\hline $\begin{array}{l}0,1 \\
0,2 \\
0,3 \\
0,4\end{array}$ & $\begin{array}{l}1,5 \\
1,5 \\
1,5 \\
1,5\end{array}$ & $\begin{array}{c}\text { sehr schwach } \\
\text { schwach } \\
\text { do. } \\
\text { stärkere inkompl. Lösg. }\end{array}$ & $\begin{array}{c}\text { sehr schwach } \\
\text { schwach } \\
\text { do. } \\
\text { stärkere inkompl. Lösg. }\end{array}$ \\
\hline
\end{tabular}

Diesem nach muss man die Möglichkeit ausschliessen, dass die oben beschriebenen Erscheinungen durch das Zusammentreffen der lipoiden und lipoidophilen Substanzen verursacht werden könnten, weil in diesem Falle die Ueberschwemmung der Blutsera mit Lezithin den hämolytischen Titer unserer Blutsera bestimmt auffällig verringern würde. Dass die präzipitierenden Sera imstande seien, mechanisch Komplementbindung hervorzurufen, wird heute schon von den namhaftesten Autoren energisch bestritten. So wäre diese Annahme zu verstehen, wenn davon die Rede wäre, dass das Komplement rein physikalisch von den Präzipitaten gebunden würde. Wir wissen ja, dass dies auch für andere, nicht spezifisch bindende Substanzen bewiesen ist (Infusorienerde, Kaolin, pflanzliche und tierische Kohle), so ist es auch Fenyvessy gelungen, mit spezifischen Präzipitaten aus Sera Komplement zu entziehen. In unseren Versuchen besteht nicht dieser Fall, weil wir ja mit vom Serum gänzlich befreiten roten Blutkörperchen gearbeitet batten. Ausserdem hatten wir, um jeder Eventualität vorzubeugen, unsere Sera auf Präzipitation untersucht, ja sogar den Präzipitationstiter eines jeden Serums bestimmt und die Resultate in einer Tabelle zusammengestellt. Wir baben daher keinen Grund, diese Episode unserer Versuche näher zu erörtern und wollen kurz nur so viel erwähnen, dass etwa $2 / 3$ unserer Sera präzipitierten, $1 / 3$ keine Präzipitation zeigte. Die Titerbestimmungen nach 
Wassermann und Schütze ergaben für das erste Drittel eine Stärke von 2-4 Einheiten, doch schien die Grösse des Präzipitationsgrades, sogar ihr Anwesendsein oder Fehlen, ganz gleichgiltig für die Stärke der Hämolyse zu sein. Im übrigen änderte im Falle Dungern und Coca nicht einmal die Anwesenbeit des Präzipitats etwas an der Wirkung des Komplements. Hier weisen wir auch auf die Resultate der mit dem Blutserum der Kaniuchen gemachten Wassermannschen Reaktion hin.

Hiernach könnte gegen die Erklärung der beschriebenen Erscheinungen noch folgender Einwurf gemacht werden, dass sich gegen die Eiweissstoffe der eingeführten Sera spezifische Eiweissantikörper gebildet hatten oder dass andere komplementbindende Stoffe eine Rolle spielten.

Dieser Umstand kommt hauptsächlich in Betracht bei dem Blutserum des gegen Paralysis immunisierten Kaninchens, wo angenommen werden kann, dass im Blute der geimpften Kaninchen Luesambozeptoren kreisen (im Sinne Citrons: Reagine), welche nach Bauer auch in der Gegenwart von normalen Hämolysinen die Reaktion verlangsamen, in Gegenwart von Antigen dagegen vollständig verhindern. (Darauf beruht die Bauersche Reaktion, welche auch durch die Kontrollversuche von Hinrichs und Behring gestützt wurden.) Um diese Verhältuisse zu beurteilen, brachten wir unsere Sera mit alkoholischem Luesantigen zusammen, neben einem mittelstarken hämolytischen System oder, mit anderen Worten, wir stellten in den Rahmen der Wassermannschen Reaktion unsere Immunsera hinein, wo sie die Stelle des Luesambozeptors vertreten sollten.

Die Reaktion machten wir in den bei der Wassermannschen Reaktion üblichen Gewichtsmengen, mit gleichen Volumina. Als Komplement verwendeten wir Meerschweinchenserum (von 1:10 $1 \mathrm{ccm}$ ), hämolytischen Ambozeptor (von 1:1000 1 ccm). Nach einer Stunde Stehen im Thermostat von $37^{\circ}$ war das Resultat komplette Lösung auch noch bei Mengen von 0,3-0,2 Immunserum bzw. Antigen. Die Immunsera inaktivierten wir vor der Reaktion, die Druck- und Temperaturverhältnisse waren dieselben wie zuyor. Wir konnten daber in der Stärke der Reaktion keinen Unterschied feststellen. Es sind daher in den gegen paralytisches Blutserum gebildeten Immunsera keine komplementbindenden Substanzen. Gegen unseren letzten Versuch könnte eingewendet werden, dass bei einem solch' starken hämolytischen System, mit dem wir bei der Wassermannschen Reaktion zu arbeiten pflegten, die geringe Menge der vielleicht nur geringe Affinität besitzenden komplementbindenden Stoffe nicht zur Geltung gelangen können, denn ver- 
gessen wir nicht, dass ,alle mit der Komplementbindungsmethode möglichen Resultate sind nur relative Werte, sie drücken das Verbältnis der Bindangsaffinität zwischen dem Komplex von Antigen und Ambozeptor und dem Komplex Hämolysin und Blut zum Komplement aus" (siehe Citron: Die Technik der Bordet-Gengouschen Komplementbindungsmethode und Kraus-Levaditi, II. Bd. S. 1087). Eben deshalb sehen wir, welche bindenden Stoffe diese Unterschiede verursachen könnten.

In erster Reihe würden also eiweissartige Stoffe eine Rolle spielen, zum Teil reine Proteine, zu denen die mit dem Blutserum injizierten Toxine and Reagine gehören, zum Tell Eiweisslipoide von ungewisser Abkunft, über deren Spezifität heute noch lebhaft gestritten wird. Die Eiweisssubstanzen verträgt der Organismus als fremdes Eiweiss nicht lange, sondern sucht sie so schnell wie möglich zu zerlegen und auszuscheiden, darauf weist die bei Bluttransfusionsversuchen auftretende und dureh gesteigerten Eiweisszerfall verursachte gesteigerte Nitrogenausscheidung hin (siehe Forster, Hári u.a.), dabei geht nach Panum und Tschirief das Serumeiweiss noch sebneller zugrunde als die roten Blutkörperchen.

In zweiter Reihe müsste man an Lezithin und andere Lipoide denken. Tatsache ist, dass im Blutserum von Paralytikern das Lezithin nach Peritz und Bornstein stark vermehrt ist. Für das Lezithin, sowie für andere lipoide und kolloide Stoffe (wie Gelatine, Glykogen, Albumose usw.) haben Mehrere komplementbindende Fähigkeiten festgestellt (Wassermann, Citron, Landsteiner, Stankovic u. a.). Gerade diese letzten Untersuchungen führten Einzelne auf die physikochemische Theorie des Komplementbindangsmechanismus zurück.

Nach Peritz bängt der positive oder negative Ausfall selbst der Wassermannschen Reaktion von den Mengenverhältnissen dieser Lipoide zu den Luestoxinen ab, ihm gelang es auch, die positive Wassermannsche Reaktion mit Lezithininjektionen zu schwächen, und mit der von ihm eingefübrten Lezithintherapie gelang es Einigen (so Subow), wenn auch nicht bei Paralysis, so doch bei Tabes objektive und subjektive bestimmte Besserung zu erzielen.

Die andere Wirkung des Lezithins folgt aus seiner aktivierenden Eigenschaft. Indem es nämlich mit bestimmten Giften in chemische oder physikalische Bindung tritt, erhöht es die Toxizität bedeutend. So kann das Lezithin besonders bei dem viel untersuchten inaktivierten Kobragift (Kyes und Sachs), bei Rizin usw. als Aktivator wirken, indem es bei beiden bämolytische Wirkung auslöst.

Beide Wirkungen beziehen sich auf niedere Konzentration des Lezithins. In höberer Konzentration löst das Lezithin schon allein rote 
Blutkörperchen, dabei noch besser ohne Immunhämolysin und Komplement (siehe Kentzler, nach welchem das Lezithin zum Komplement grössere Affinităt zeigt, wie zu den roten Blutkörperchen). Alle diese Wirkungen des Lezithins waren durch unsere oben beschriebenen Versuche ausgeschlossen, da die Lezithininjektionen die hämolytischen Eigenschaften unserer Sera nicht im geringsten änderten. Es wäre auch schwer begreiflich, dass eine solch' verhältnismässig labile Verbindung, wie das Lezithin, im gesunden tierischen Organismus längere Zeit unverändert kreisen könnte, da wir schon von ihm wissen, dass es zu spontaner Autooxydation neigt. Im übrigen hat auch Max Kauffmann bei Hysterie den Lezithingehalt des Blutes vermehrt gefunden, und er ist überzeugt, dass dies bei einem grossen Teile der Geisteskranken der Fall ist.

Anders muss die Vermehrung des Lezithins im Blute von Paralytikern beurteilt werden, welches infolge des Zerfalls der Elemente des durch Toxine angegriffenen Nervensystems und der blutbildenden Organe fortwährend neu gebildet wird. (Peritz und Bornstein wiesen auch Lezithinarmut des Knochenmarks und des Zentralnervensystems nach.) Dass man tatsächlich mit Recht einen raschen Zerfall des ins Blut gelangten Lezithins annehmen kann, zeigt Kanffmann (Beiträge zur Pathol. des Stoffwechsels usw. 1908. S. 30), der durch Stoffwechseluntersuchung wach einem schweren paralytischen Anfall im Urin des Kranken eine Gesamtmenge der Phosphorsäure von $8,855 \mathrm{~g}$ fand ein sehr hoher Wert. Nach ihm kann man hier auf eine Loslösung und Zerfall von phosphorhaltigen Lipoidstoffen des zentralen Nervensystems, also in erster Linie auf Lezithin schliessen.

Man könnte in unseren Fälen noch an die Isolysine bzw. Antiisolysine denken, welche sowohl in normalem Blutserum, als auch unter patbologischen Verhältnissen nachgewiesen sind; nach mehreren Autoren kamen sie im letzten Falle sogar in hohen Werten, in hohem Prozentgehalt vor, so dass man sie bei malignen Tumoren auch zu diagnostischen Zwecken verwendete, wegen ihrer Unzuverlässigkeit konnten sich diese Reaktionen jedoch nicht einbürgern (Donath, Micheli, Kulmann, Richarts). An diese, als auch an die Gegenwart von Antiisolysinen dachten wir anfangs und machten mit den als Antigen dienenden Blutsera zwei Reihen hämolytiscber Versuche, nach den Dosen der ersten Tabelle, mit den ihnen homologen roten Blutkörperchen, das Resultat war jedoch immer vollständig negativ, so dass wir sie als Ursache der obigen Unterschiede in der Hämolyse ganz ausschliessen konnten.

Nebenbei erwähnen wir noch, dass wir gleichzeitig auch an Autolysine dachten (welche nach Kratz, Donath, Landsteiner u. a. bei paroxysmaler Hämoglobinurie vorkommen, und bei welcher Krankheit heute 
Lues schon eine wichtige anamnestische Rolle spielt), und machten in mehreren Fällen mit paralytischem und zum Vergleich auch mit praecoxem und normalem Serum und roten Blutkörperchen den DonathLandsteinerschen Versuch nach der Vorschrift (Blutserum, rote Blutkörperchen 5:1, eine halbe Stunde in Eiswasser, dann eine Stunde im Thermostat von $37^{\circ}$ ), aber immer mit negativem Erfolg.

In die Frage der sehr bestrittenen Antikomplemente liessen wir uns wegen ihrer sehr hypothetischen Existenz gar nicht ein.

Von Veränderungen in der Avidität des Komplements kann nicht die Rede sein, da die Reaktion konstant und allgemein zu sein scheint.

Dieses wären, unserer bescheidenen Meinung nach, die Einwendungen, die gegen das Wesen der Reaktion gemacht werden könnten. Nach diesem nehmen wir nun die durch die ergänzenden Versuche gestützte und unter allen uns am einfachsten und logischsten scheinende Hypothese endgiltig an und glauben, dass daraus auch das verschiedene Verhalten der drei verschiedenen Blutkörperchenarten zu erklären sei.

Wir sahen nämlich, dass innerhalb der Unterschiede in der hämolytischen Stärke der Sera sich auch nach den roten Blutkörperchen sebr auffällige Unterschiede zeigten. Nach unserer Erklärung sind die im Blutserum von Paralytikern befindlichen Stromarezeptoren entweder nur an Zahl verringert, oder auch in der Affinität geschwächt. Dieselbe Annabme ist daher auch für diejenigen Rezeptoren berechtigt, welche die Lysis verursachen; es wäre nämlich schwer, sich vorzustellen, dass die bei der Paralysis supponierten Toxine den Rezeptorengruppen der roten Blutkörperchen gegenüber sich elektiv verhalten sollten, besser gesagt, die Antigene angreifen sollten und die lytische Funktion besitzenden Rezeptoren verschonen sollten, wenn überhaupt von einer Differenzierung der beiden Rezeptorengruppen die Rede sein kann.

Diese von den Toxinen auf die Rezeptoren ausgeübte Wirkung muss nicht eine vollständige Devastation sein, es ist genug, wenn sie in ihrer Molekularstruktur feinere Verschiebungen verursachen, mit denen sie schon die Vorbedingungen der Komplexbildung unterbricht.

Absichtlich halten wir uns noch an die Lehren von Ehrlichs Schule, weil die physikalisch-chemischen Erklärungen der Hämolyse, nach denen hier von einer Gradabschwächung der Dispersität der Stromakolloide die Rede wäre, die gewisse, den Kolloidzustand verändernde Faktoren hervorrufen würden, eine noch nicht genug gefestete Basis bieten, um auf ihnen neue Resultate aufzubauen.

Bevor wir diejenige Frage berühren, ob unsere Annahme mit der Erklärung der in Rede stehenden Krankbeiten übereinstimmt, müssen wir noch ergänzend die Resultate folgender neuer Versuche mitteilen. 
Die Versuche Landsteiners bezüglich der kolloiden Kieselsäure waren uns bekannt, nach welchen es ihm gelang mit der 0,1 proz. Lösung von der nach Grimaux hergestellten Kieselsäure mit dem Komplement von frischem Kaninchenserum und den Blutkörperchen vom Schafe Hämolyse zustande zu bringen. Nach seiner Ansicht wäre bier davon die Rede, dass die kolloide Kieselsäure die Komplemente adsorbiert und auf die roten Blutkörpercben übertragen, das heisst das Wesen der Sache ist an dieser Stelle mit der kolloiden Wirknng der Kieselsäure in Beziehung.

Demmach dachten wir folgendermassen, wenu das wahr ist, dass die kolloide Kieselsäure zu solcher Komplementübertragung fähig ist, so wird sie in unseren Versuchen die spezifischen Immunkörper dort ersetzen, wo diese mangels der als Antigen dienenden Rezeptoren (siehe oben) überhaupt nicht, oder wenigstens in viel kleinerer Anzahl sich ausbilden konnten, hier aber, wo jene in entsprechender Anzahl gebildet wurden, wird sie gleichfalls die Hämolyse verstärken, wenn auch nicht im Verhältuis (siehe die Beobachtungen von Bordet, Ehrlich, Morgenroth) bezüglich der Bindungskapazität der roten Blutkörperchen bei Zugabe von fraktioniertem Hämolysin.

Die kolloide Kieselsäure haben wir nach Graham hergestellt: $\mathrm{Zu}$ $100 \mathrm{~g}$ Wasserglas, das heisst Natriummetasilikat, gaben wir $20 \mathrm{~g}$ 10 proz. HCl, dann dialysierten wir die Flüssigkeit durch einen aus Pergamentpapier improvisierten Dialysator unter Benutzung des zirkulierenden Wassers der Wasserleitung, das die Moleküle des kristalloiden Kochsalzes und der Salzsäure mit sich reissend, die ursprüngliche Konzentrationsverschiedenheit aufrecht zu halten berufen war. Nachdem sowohl die Salzsäure, als auch das Kochsalz nach Grahams früheren Versuchen bezüglich der, von der Natur des Stoffes abhängigen Diffusionsgeschwindigkeit, vielen andern Stoffen vorangeht, gab, mit dem vorhererwähnten Mengen arbeitend, die aus dem äusseren Wasser entnommene Probe schon nach ein paar Stunden mit $\mathrm{AgNO}_{3}$ keinen Niederschlag, also ist nach Entfernung der Chloride das Kieselsäurehydrosol allein anwesend. Mit dessen 1 proz. Lösung machten wir die Reaktion mit folgendem Ergebnis: (Zum Vergleich teilen wir auch die hämolytischen Fähigkeiten desselben Blutserums vor der Hinzugabe der Kieselsäure mit.)

Die Tabelle IV befestigt daher sowohl die Versuche Landsteiners als auch unsere Annabme, dass in dem Blutserum des gegen paralytisches Blutserum immunisierten Kaninchens weniger spezifische Immunbämolysine sich bildeten.

Es erübrigt noch von den Sublimatinjektionen zu sprechen, welche wir unsern, mit. den obigen Sera behandelten Kaninchen in die Ohrvene 


\section{Tabelle IV.}

Die hämolytische Wirkung der Blutsera der Kaninchen Nr. 17 (paralyt.), Nr. 23 (praec.), Nr. 11 (norm.) nach Hinzugabe von kolloider Kieselsäure (1 pCt.).

\begin{tabular}{|c|c|c|c|c|}
\hline \multirow{2}{*}{$\begin{array}{l}\text { Kaninchen- } \\
\text { blutserum } \\
\text { Nr. } 17 \\
\text { ccm }\end{array}$} & \multirow{2}{*}{$\begin{array}{l}5 \text { proz.Suspen- } \\
\text { sion von para- } \\
\text { lyt.roten Blut- } \\
\text { körperchen } \\
\quad \text { ccm }\end{array}$} & \multirow{2}{*}{$\begin{array}{l}10 \text { proz. Kol- } \\
\text { loide Kiesel- } \\
\text { säure } \\
\text { com }\end{array}$} & \multicolumn{2}{|c|}{ Resultat 2 Std. Thermostat } \\
\hline & & & ohne Kieselsäure & mit Kieselsäure \\
\hline $\begin{array}{l}0,1 \\
0,2 \\
0,3 \\
0,4\end{array}$ & $\begin{array}{l}1,5 \\
1,5 \\
1,5 \\
1,5\end{array}$ & $\begin{array}{l}0,1 \\
0,3 \\
0,5 \\
0,8\end{array}$ & $\begin{array}{l}\text { keine Lösung } \\
\text { in Spuren } \\
\text { löst kaum } \\
\text { sehr schwach }\end{array}$ & $\begin{array}{l}\text { sehr schwach } \\
\text { schwach } \\
\text { ziemlich stark } \\
\text { stark }\end{array}$ \\
\hline
\end{tabular}

\begin{tabular}{|c|c|c|c|}
\hline \multirow{2}{*}{$\begin{array}{c}\text { Kaninchen- } \\
\text { blutserum } \\
\text { Nr. } 23 \\
\text { ccm }\end{array}$} & \multirow{2}{*}{$\begin{array}{l}5 \text { proz. Suspen- } \\
\text { sion von-praes. } \\
\text { roten Blut- } \\
\text { körperchen } \\
\text { cem }\end{array}$} & \multicolumn{2}{|c|}{ Resultat, 2 Std. Thermostat } \\
\hline & & ohne Kieselsäure & mit Kieselsäure \\
\hline $\begin{array}{l}0,1 \\
0,2 \\
0,3 \\
0,4\end{array}$ & $\begin{array}{l}1,5 \\
1,5 \\
1,5 \\
1,5\end{array}$ & $\begin{array}{c}\text { schwach } \\
\text { do. } \\
\text { ziemlich stark } \\
\text { stark }\end{array}$ & $\begin{array}{c}\text { schwach } \\
\text { ziemlich stark } \\
\text { stark } \\
\text { beinahe komplett }\end{array}$ \\
\hline \multirow{2}{*}{$\begin{array}{l}\text { Kaninchen- } \\
\text { blutserum } \\
\text { Nr. } 11 \\
\text { ccm }\end{array}$} & \multirow{2}{*}{$\begin{array}{l}\text { 5proz.Suspens. } \\
\text { von normalen } \\
\text { menschl. Blut- } \\
\text { körperchen } \\
\text { ccm }\end{array}$} & \multicolumn{2}{|c|}{ Resultat 2 Std. Thermostat } \\
\hline & & ohne Kieselsäure & mit Kieselsäure \\
\hline $\begin{array}{l}0,1 \\
0,2 \\
0,3 \\
0,4\end{array}$ & $\begin{array}{l}1,5 \\
1,5 \\
1,5 \\
1,5\end{array}$ & $\begin{array}{l}\text { sehr schwach } \\
\text { schwach } \\
\text { do. } \\
\text { ziemlich stark }\end{array}$ & $\begin{array}{c}\text { schwach } \\
\text { ziemlich stark } \\
\text { do. } \\
\text { stark }\end{array}$ \\
\hline
\end{tabular}

applizierten und welche nicht weniger interessante Resultate ergaben, indem sie die Richtigkeit unserer Folgerungen in allem bestätigten. Bei der Beurteilung des voneinander abweichenden Verhaltens der roten Blutkörperchen nämlich hätte sich von selbst die einfache, aber nicht vielsagende Annahme ergeben, dass hier eigentlich von der Resistenzverschiedenheit jener die Rede ist. Wenn dieses richtig ist, so sind dem obigen gemäss die roten Blutkörperchen der Paralytiker viel resistenter als die normalen roten Blutkörperchen, diejenigen der Praecoxen hingegen bedeutend weniger resistent. Dies wäre garnicht unerwartet, wenn wir 
an die Untersuchungen von Kraus, Pötzl, Ranzi und Ehrlich denken nach denen die Resistenz der roten Blutkörperchen gegenüber dem Kobralezithid bei Karzinomkranken in $50-78$ pCt. der Fälle, und was hier besonders wichtig ist, bei Lues in $78 \mathrm{pCt}$. erhöht ist. (Ausserdem in k]einerem Prozentsatz auch bei Typhus und Lyssa.)

Von einer Lösung von Hydrarg. bichlor. corros. $0,3+\mathrm{NaCl} 1,0 \mathrm{~g}$ + aqu. dest. $30 \mathrm{~g}$ spritzten wir unsern Kaninchen je $2 \mathrm{ccm}$ ein, und nahmen von allen 3 Kaninchen 6 Stunden nach der Injektion Blut. Das nach Defibrinierung und Zentrifugierung gewonnene Serum wies auf in vivo ausgebildete Sublimat-Hämolyse, beziehungsweise Hämoglobinurie. Diese war am grössten bei den mit paralytischem, am kleinsten bei den mit praecoxem, von mittlerer Grösse bei unsern mit normalem Blutserum behandelten Kaninchen.

Daraus kann man mit Recht folgern, dass in dem Blute der Paralytiker solche Toxine kreisen, die nicht nur ibre eignen roten Blutkörperchen und deren Rezeptoren angreifen. sondern auch die Widerstandskraft der roten Blutkörperchen des Kaninchens verringern. Bei Praecox-Kranken findet eine Rezeptorenẗberproduktion statt. Nach den, die chemische Natur der Rezeptoren charakterisierenden Untersuchungen (siehe oben), sind diese mit Proteinen verbundene Lipoidstoffe oder reine Lipoide, obgleich die Frage noch nicht ganz geklärt ist (Landsteiner, Eisler, Bang, Forssmann). Durch die Versuche von Sellei und Detre wissen wir aber, dass die Lipoide die Sublimathämolyse hindern; aus diesem folgt daher, dass die lipoiden oder eiweisslipoiden Rezeptoren auch in vivo die Wirkung des, in das Blut unserer Kaninchen applizierten Sublimats in grossem Masse hindern werden.

Die mit den Sera nach der ersten Tabelle angestellte Reaktion war sehr ausgesprochen und stimmte mit der vor der Einspritzung vorgenommenen in allem überein.

Tabelle V.

Das Verhalten der Sera der Kaninchen Nr. 14 (paralyt.), Nr. 20 (praec.), Nr. 12 (norm.) homologen roten Blutkörperchen gegenüber nach Quecksilberinjektion.

\begin{tabular}{|c|c|c|c|}
\hline \multirow{2}{*}{$\begin{array}{c}\text { Blutserum des } \\
\text { Kaninchens } \\
\text { Nr. } 14 \\
\text { ccm }\end{array}$} & \multirow{2}{*}{$\begin{array}{l}5 \text { proz. Suspen- } \\
\text { sion von para- } \\
\text { lyt. roten Blut- } \\
\text { körperchen } \\
\text { ecm }\end{array}$} & \multicolumn{2}{|c|}{ Resultat } \\
\hline & & $\begin{array}{c}\text { Vor der } \\
\text { Quecksilberinjektion }\end{array}$ & $\begin{array}{c}\text { Nach der } \\
\text { Quecksilberinjektion }\end{array}$ \\
\hline $\begin{array}{l}0,1 \\
0,2 \\
0,3 \\
0,4\end{array}$ & $\begin{array}{l}1,5 \\
1,5 \\
1,5 \\
1,5\end{array}$ & $\begin{array}{c}\text { keine Lösung } \\
\text { löst kaum } \\
\text { sehr schwache Lösung } \\
\text { do. }\end{array}$ & $\begin{array}{c}\text { keine Lösung } \\
\text { löst kaum } \\
\text { sehr schwache Lösung } \\
\text { do. }\end{array}$ \\
\hline
\end{tabular}




\begin{tabular}{c|c|c|c}
\hline \hline $\begin{array}{c}\text { Blutserum des } \\
\text { Kaninchens } \\
\text { Nr. } 20\end{array}$ & $\begin{array}{c}\text { 5 proz. Suspen } \\
\text { sion v praec. } \\
\text { roten Blut- } \\
\text { körperchen } \\
\text { ecm }\end{array}$ & $\begin{array}{c}\text { Vor der } \\
\text { Quecksiberinjektion }\end{array}$ & $\begin{array}{c}\text { Nach der } \\
\text { Quecksilberinjektion }\end{array}$ \\
\hline 0,1 & 1,5 & $\begin{array}{c}\text { sehr schwache lösung } \\
\text { schwache Lösung } \\
\text { ziemlich stark } \\
\text { stark }\end{array}$ & $\begin{array}{c}\text { sehr schwache Lösung } \\
\text { schwache Lösung } \\
\text { ziemlich stark } \\
\text { stark }\end{array}$ \\
0,3 & 1,5 & &
\end{tabular}

\begin{tabular}{|c|c|c|c|}
\hline \multirow{2}{*}{$\begin{array}{l}\text { Blutserum des } \\
\text { Kaninchens } \\
\text { Nr. } 12 \\
\text { cem }\end{array}$} & \multirow{2}{*}{$\begin{array}{l}5 \text { proz. Suspen- } \\
\text { sion von norm. } \\
\text { menschl. roten } \\
\text { Blutkörperch. } \\
\text { cem }\end{array}$} & \multicolumn{2}{|c|}{ Resultat } \\
\hline & & $\begin{array}{c}\text { Vor der } \\
\text { Quecksilberinjektion }\end{array}$ & $\begin{array}{c}\text { Nach der } \\
\text { Quecksilberinjektion }\end{array}$ \\
\hline $\begin{array}{l}0,1 \\
0,2 \\
0,3 \\
0,4\end{array}$ & $\begin{array}{l}1,5 \\
1,5 \\
1,5 \\
1,5\end{array}$ & $\begin{array}{l}\text { Zeine Lösung } \\
\text { in Spuren } \\
\text { sehr schwach } \\
\text { schwach }\end{array}$ & $\begin{array}{l}\text { keine Lösung } \\
\text { in Spuren } \\
\text { sehr schwach } \\
\text { sehwach }\end{array}$ \\
\hline
\end{tabular}

Aus diesem Vergleich geht daher hervor, dass die Quecksilberinjektion die hämolytische Fähigkeit der Sera in keiner Richtung beeinflusst. Quecksilberinjektionen machten wir deshalb, weil uns jene Versuche bekannt waren, nach welchen das Quecksilber in vivo, wie in vitro die Komplementbindung hindert.

Ausserdem nahmen wir mit Quecksilber und Lezithin in vitro, weiterhin auch mit den alkoholischen Extrakten unserer Sera Versuche vor; da diese aber weder pro noch contra beweisen, teilen wir sie nicht mit.

Diesem nach haben wir noch bezüglich der mit dem normalen Kaninchenserum in sehr geringem Grad ausgesprochenen, in der ersten Tabelle ersichtlichen Hämolyse nur noch das zu bemerken, dass wir es in dem Falle mit, in dem Kaninchenserum ständig vorbandenen normalen Hämolysinen zu tun haben, deren Anwesenheit nach einigen (Remy) Chancen zur gesteigerten Bildung von Immunhämolysinen bietet. "Geisteskranke sind Gehirnkranke" sagt Kauffmann, und wenn wir uns auch nicht in allem mit denjenigen einverstanden erklären, die teils ihre Tierversuche zur Feststellung der vegetativen Zentren der Rinde überschätzen, oder bei der Debertragung derselben auf den llenschen nicht genügend Kritik übten, teils die körperlichen Erscheinungen von funktionellen Neurosen auf solche zurückführen wollen, so sind wir doch dessen gewiss, dass die höhern Reflexbögen und die dazugehörigen Zentren 
nicht nur der Sitz der Psyche, und damit auch der psychomotorischen und und sensorischen Funktionen sind, sondern auf alle Körperorgane und auf deren Funktion übertragen, einen grossen Einfluss ausüben. Abgesehen davon, stehen angesehene Autoren, so in erster Reihe $\mathrm{Kräpelin} \mathrm{bezüglich}$ der Paralysis auf dem Standpunkt, dass diese, ohne hier die Gründe zu analysieren im Endergebnis eine allgemeine Ernährungsstörung ist "bei der die Hirnerkrankung $z$ war die wichtigste und auffallendste, aber doch nur eine Teilerscheinung bildet." (Kräpelin: Psychiatrie 1910). Er führt dafür als Beweis in erster Linie die symptomatische Aehnlichkeit mit der Autointoxikation, weiterhin die anatomische Veränderung der innern Organe Ganglienzellenveränderungen etc. an.

Aber ob das noch in dem Organismus kreisende Luesvirus (siehe Kraepelins ungenannten Arzt, der bei neun, mit Syphilisvirus geimpften Kranken in keinem Falle eine primäre Sklerose hervorrufen konnte) oder die Folgen einer solchen Autointoxikation vorhanden sind, die schädliche Wirkung dieser auf die roten Blutkörperchen des Kaninchens ergibt sich in obigem Zusammenhange von selbst, ebenso wie auf dessen ganzen Organismus (200-500g Gewichtsverlust, siehe oben).

In Bezug auf die Pathogenese der Dementia praecox herrscht auch heute noch die allgemein angenommene Ansicht, dass sie in der Störung der inneren Sekretion der Geschlechtsdrüsen besteht (Kraepelin); nach Herrn Prof. Lechner besteht sie in deren Hypersekretion.

In neuerer Zeit führen sie mehrere Autoren in demselben Sinne auf die Glandula thyreoidea zurück, und einige berichten auch von sehr guten Wirkungen einer darauf gerichteten Behandlung (z. B. Levis on, Berkeley, Judin, u. a). Hier müssen wir noch die schon lange geschebenen, aber noch nicht publizierten Beobachtungen Herrn Prof. Lechners erwähnen, nach welchen bei katatonischen Anfällen die Glandula thyreoidea eine ausgesprochene Vergrösserung zeigte. Ebenso lauten auch die Beobachtungen von Dr. Borsos. - Uebrigens haben neuerdings mehrere ihre Ansicht dahin ausgesprochen, dass zwischen den Funktionen der Glandula thyreoidea und der Glandula sexualis ein engerer Zusammenhang besteht. Daneben kommt bei Praecox auch das in Betracht, dass die hyperkinetischen und hypotonischen Zustände der Muskulatur unter grossen Abfällen wechseln. Wir wissen aber, dass die Muskulatur die Hauptstätte der Oxydationsprozesse ist und welch grosse Rolle sie für den Wassergehalt des Organismus spielt. Aus der Störung dieser letztern Faktoren ergibt sich von selbst, dass die chemische Koordination bei PraecoxKranken schwer leidet. Bei solcher Störung des Stoffwechsels können Autointoxikationsprodukte (sekundär) in die Blutbahn geraten, anderseits auch die Produkte der erwähnten gestörten inneren Sekretion (primär), 
Unterschiede zwischen dem Blutserum von Paralytikern und Praecoxen. 231

welche summiert oder einzeln, auch aúf die zelligen Elemente des Blutes Einfluss ausüben. Auf die reizende Wirkung dieser ist aller Wabrscheinlichkeit nach die von vielen beobachtete Hyperlenkozytose, Lymphozytose usw. bei Praecox zurückzuführen.

Unserer Meinung nach repräsentieren die genannten Stoffe auch für die roten Blutkörperchen ständige Reize in dem Sinne, dass (nach den Lehren von Ehrlichs Schule) sie diese zu gesteigerter Rezeptorenbildung veranlassen.

Darin sehen wir die Begründung der von uns beobachteten Verschiedenheiten zwischen paralytischem und praecoxem Serum.

Von diesen Unterschieden erhoffen wir uns einen sichern Erfolg, in erster Reihe in den zweifelhaften Fällen, in denen die Diagnose zwischen Paralysis und Dementia praecox schwankt, was nicht so selten der Fall ist (siehe Kraepelin: Psychiatrie 1910), und bei denen wir uns oft mit unserer vollständigen Hilfslosigkeit abfinden müssen, andererseits sehen wir in der, durch uns inaugurierten Reaktion nach deren Ausarbeitung zu differenziell-diagnostischen Zwecken auch eine sichere Basis zur selbständigen Diagnose der beiden Krankheiten.

Jedenfalls sind auf diesem Gebiete noch ergänzende Untersuchungen nötig. Hauptsächlich auf die Beziehungen der Lues zu den übrigen Geisteskrankheiten und zu funktionellen Neurosen müsste man die Untersuchungen ausdehnen (aus begreiflichen Gründen käme dann auch die Manie und Amentia besonders in Frage). Wir hoffen jedoch, dass anch diese, wie die bisherigen ohne Ausnahme uns in dem Glauben in die diagnostische Verwendbarkeit unserer Reaktion nur bestärken werden.

Die Ergebnisse unserer Untersuchungen können wir kurz in folgendem zusammenfassen:

1. Die Kaninchenimpfungen mit paralytischem Serum führten ständig zu 200-500g Gewichtsverlust.

2. Bei Praecox zeigte sich in 2 Fällen auf solche Impfungen schwere Nephritis, bei Paralyse in keinem einzigen Fall.

3. Keratitis, Pneumonie fanden wir in keinem einzigen Fall.

4. Die hämolytiscbe Wirkung der Blutsera der gegen die Sera immunisierten Kaninchen wird durch Immunhämolysine verursacht.

5. Die als Antigene dienenden Stromarezeptoren sind in dem paralytischen Blutserum in sehr geringer Menge oder molekulär verändert vorhanden, während das Blutserum der Praecoxkranken an Hämolysinantigenen reich ist.

6. Die Wirkung der Agglutinine, Präzipitine, Eiweissantikörper, Lipoide, Antiisolysine bei den obigen Differenzen in der Stärke der Hämolyse kann mit vollem Recht ausgeschlossen werden. 
232 Dr. Ladislaus Benedek und Dr. Stefan Deák, Unterschiede usw.

7. Die kolloide Kieselsäure ist im Stande, die Wirkung der Immunhämolysine in vitro bis zu einem gewissen Grade zu vertreten.

8. Sublimat (als Blutgift) gegenüber zeigen die roten Blutkörperchen der mit Paralytiker-Blutserum geimpften Kaninchen eine verringerte, diejenigen der mit praecoxem Serum geimpften eine gesteigerte Resistenz.

9. Lezithin und Quecksilberchloridinjektionen beeinflussen die hämolytische Wirkung der Immunhämolysine in keiner Weise.

Nach der Registrierung unserer Resultate wollen wir nicht versäumen Herrn Prof. Dr. Karl Lechner unsern innigsten Dank auszusprechen für sein warmes Interesse und Unterstützung, durch welche er hervorragend dazu beigetragen hat, dass unsere Arbeit von Erfolg gekrönt wurde.

\section{Literaturverzeichnis.}

Citron, Med. Klinik. 1908. No. 3. - Berl. klin. Wochenschr. 1908. Nr. 19.

- Krans-Levaditi, Handb. der Immun.-Forschung. 1910. II. Bd.

Duntonn, L., The oylilik form of Dem. praec. The americ. Journal of Insanity. 1910. 66. 465.

Dungern u. Coca, Biochem. Zeitschr. Bd. XIII.

Fenyvessy, B., Magy. orv. Archiv. 1910. S. 154.

Hoppe-Seyler, Phys.-Path. chem. Analyse. 1909.

Kauffman n, M., Beitr. zurPath. d. Stoffwechsels b. Psychosen. I., II. u. III. Teil. Kentzler, G., Magy. orv. Archiv. 1911. H. 2.

Királyfi, G., Magy. orv. Archiv. 1910. S. 270.

Kraepelin, Psychiatrie. 1904, 1909 u. 1910.

Meyer, E., Die Ursachen der Geisteskrankheiten. 1907.

Molnár, B., Magy. orv. Archiv. 1910. H. I u. H. VI.

Peritz, Berl. klin. Wochenschr, 1908. Nr. 2.

Pick, E., Darstellung der Antigene mit chem. u. phys. Method. Kraus-Levaditi. 1908. Bd. I.

Porges u. Meyer, Berl. klin. Wochensehr. 1907. No. 51 u. 1908. Nr. 15. Porges, Ueber Kolloide und Lipoide in ihrer Beziehung zur Immunitätslehre.

Kraus-Levaditi. Bd. II.

Ranzi, E., Serumrealition bei malignen Tumoren e. 0.

Rusznyák, Magy. orv. Archiv. 1911. H. II u. H. V.

Sacbs, Antigene tierischen Ursprungs und Haemolysine und Cytotoxine des

Blutserums. (Kraus-Levaditi: Handb. d. Immun.-Forschung.)

Siebert-Mironescu, Deutsche med. Wochenschr. 1911, 45.

TThán Károly, Kisérl. Chemia elemei. 1906. Bd. II.

Urstein, Die Dementia praecox und ihre Stellung etc. 1909.

Wassermann u. Citron, Zeitschr. f. exper. Path. u. Ther. 1907. Bd. IV. Wassermann, Wien. klin. Wochenschr. 1908. Nr. 21.

Weil u. Braun, Wien. klin. Wochenschr. 1908. Nr. 2.

Weiss, 0., Pflügers Archiv. 1896. Bd. 65. 